\title{
Description of Pseudorhabdosynochus seabassi sp. n. (Monogenea: Diplectanidae) from Lates calcarifer and revision of the phylogenetic position of Diplectanum grouperi (Monogenea: Diplectanidae) based on rDNA sequence data
}

\author{
Xiang Y. Wu ${ }^{1}$, An X. Li ${ }^{1}$, Xing Q. Zhu ${ }^{2}$ and Ming Q. Xie ${ }^{1}$ \\ ${ }^{1}$ Centre for Parasitic Organisms, School of Life Sciences, Sun Yat-sen University, 135 Xingang West Street, Haizhu District, \\ Guangzhou 510275, Guangdong Province, The People's Republic of China; \\ ${ }^{2}$ Laboratory of Parasitology, College of Veterinary Medicine, South China Agricultural University, 483 Wushan Street, Tianhe \\ District, Guangzhou 510642, Guangdong Province, The People's Republic of China
}

Key words: Pseudorhabdosynochus seabassi, Diplectanum grouperi, PCR, phylogeny, Lates calcarifer

\begin{abstract}
Pseudorhabdosynochus seabassi sp. n. (Monogenea: Diplectanidae) from the gill filaments of Lates calcarifer Bloch, a marine teleost fish held in floating sea cages in Guangdong Province, China, is described based on morphological observations and molecular data. The shapes of the male copulatory organs (MCO) of Pseudorhabdosynochus spp. were the focus of this study. The typical proximal part of the MCO in most species of Pseudorhabdosynochus is reniform, heavily sclerotized, and divided into four chambers. However, the new species from L. calcarifer has a bulbous proximal region with four concentric layers of apparent muscular origin, instead of a reniform structure with four compartments. This organ is also different in Diplectanum grouperi Bu, Leong, Wong, Woo et Foo, 1999, being sclerotized, cup-shaped, wide proximally with four concentric muscular layers and tubular distally. The 3' terminal portion of the small subunit ribosomal RNA gene (ssrDNA) and the 5' terminal region (domains C1-D2) of the large subunit ribosomal RNA gene (lsrDNA) were used to reconstruct the phylogenetic relationships of $P$. seabassi and $D$. grouperi with related taxa utilizing maximum-parsimony and neighbour-joining methods. Phylogenetic analyses unequivocally placed D. grouperi amongst Pseudorhabdosynochus using either ssrDNA or 1srDNA data. All species of Pseudorhabdosynochus (including D. grouperi) used in this study clustered together, inferring monophyly. Based on molecular phylogenetic evidence, we propose that D. grouperi from Epinephelus coioides Hamilton be transferred to Pseudorhabdosynochus as P. grouperi comb. n.
\end{abstract}

Diplectanids are a group of monogeneans that mainly parasitize the gills of serranid fish and have a world-wide distribution (Oliver 1993). Many species of these monogeneans occur in cultured fish and are of considerable economic importance (e.g., Nash et al. 1987, Leong and Wong 1990, Leong 1994). Traditionally, classification of the Diplectanidae Bychowsky, 1957 has been based, to a large extent, on morphology of the sclerotized components of the haptor (Beverley-Burton and Suriano 1981). Two genera of the family are of particular interest because of controversies regarding the taxonomic status and phylogenetic positions of some species within them, and have been the focus of a number of studies (e.g., Oliver 1968, Kritsky and Beverley-Burton 1986). One, Diplectanum Diesing, 1858, the type genus of the family, is characterized in part by presence of a haptor which is constricted from the body proper, with two pairs of hamuli, three transverse bars, and dorsal and ventral squamodiscs consisting of concentric rows of sclerites (Yamaguti 1963). The other is Pseudorhabdosynochus Yamaguti, 1958, erected to accommodate P. epinepheli Yamaguti, 1958. Subsequently, Oliver (1968) erected Cycloplectanum for Diplectanum americanum Price, 1937, whose inner row of elements in the squamodisc forms a complete ring, distinguishing it from Diplectanum. The nomenclature and taxonomy of species in Cycloplectanum and Pseudorhabdosynochus has since become controversial and confusing. Beverley-Burton and Suriano (1981) considered that the squamodiscs of Cycloplectanum spp. showed interspecific variation in number and shape of rows, in degree of sclerite fusion and overlap pattern, and these variations should not be considered of prime importance in generic separation. They amended the diagnosis of Cycloplectanum and emphasised the importance of the unique structure of the terminal genitalia (both the male copulatory organ $[\mathrm{MCO}]$ and vagina). Considering the confusing nomenclature in these genera, Kritsky and Beverley-Burton (1986) presented a historical review and considered Cycloplectanum a junior synonym of Pseudorhabdosynochus Yamaguti, 1958.

So far, six diplectanids have been reported from Lates calcarifer, two belonging to Pseudorhabdosynochus, namely P. latesi Tripathi, 1955 and $P$. monosquamodiscusi Balasuriya et Leong, 1995. In this paper, a new species of Pseudorhabdosynochus collected from gills of

Address for correspondence: A.X. Li, Centre for Parasitic Organisms, School of Life Sciences, Sun Yat-sen University, 135 Xingang West Street, Haizhu District, Guangzhou 510275, Guangdong Province, The People's Republic of China. Phone: ++86 208411 5113; Fax: +86 2084115113 ; E-mail: axli2004@163.com 
L. calcarifer is described based on morphological characters. However, there are limitations using morphological approaches as some studies on Gyrodactylidae (Mo 1991) have demonstrated variation in the morphology of haptoral sclerites on which Diplectanidae and most other monogeneans are mainly based (Oliver 1987).

Molecular approaches using genetic markers in small and large subunit ribosomal DNA (ssrDNA and lsrDNA) offer alternatives and complement morphology for identification and systematics of monogeneans (e.g., Cunningham et al. 1995, Mollaret et al. 1997, Littlewood et al. 1998, Olson and Littlewood 2002). A few studies have examined phylogenetic relationships of monogeneans at the subclass and family levels using molecular approaches (Mollaret et al. 2000, Jovelin and Justine 2001, Olson and Littlewood 2002). However, little is known about phylogenetic relationships within Monogenea at the generic level, although this could be important to understand host-parasite relationships (Desdevises et al. 2000, 2002, Huyse et al. 2003, Šimková et al. 2003). Therefore, another objective of the present study is to investigate the phylogenetic status of Diplectanum grouperi Bu, Leong, Wong, Woo et Foo, 1999 which parasitizes the gills of Epinephelus coioides Hamilton and is very similar to Pseudorhabdosynochus spp. in terms of host species and morphological features, such as the four muscular layers in the proximal part of MCO, which is similar to that of $P$. latesi and $P$. monosquamodiscusi. It was described, however, as a species of Diplectanum considering the cupshaped MCO as a whole. We used the 3' terminal portion of ssrDNA and the 5' terminal region of lsrDNA (domains C1-D2), as both have been widely used to estimate phylogenetic relationships among monogeneans (e.g., Cunningham et al. 1995, Mollaret et al. 1997, Littlewood et al. 1998, Desdevises et al. 2000, Mollaret et al. 2000, Chisholm et al. 2001, Jovelin and Justine 2001, Olson and Littlewood 2002). The validity and phylogenetic position of the new species described here was also confirmed by molecular evidence.

\section{MATERIALS AND METHODS}

Parasites. Host fish cultured in floating sea cages in the South China Sea were caught and identified to species according to previous descriptions (Cheng and Zhen 1987). Parasites were excised carefully from gills of freshly killed fish. Some parasites were fixed with Bleasure's glue (Acacia gum $17.25 \%$, glycerin $13.79 \%$, chloral hydrate $34.48 \%$, distilled water $34.48 \%$ ) and their sclerotized parts examined under a dissecting microscope. Parasites were identified to species morphologically according to existing keys and descriptions (Beverley-Burton and Suriano 1981, Liang and Leong 1991, Bu et al. 1999, Wu et al. 2000, Zhang et al. 2001). In total, nine described parasite species were studied in the present study; their codes, numbers, host species, geographical origins and GenBank $^{\mathrm{TM}}$ accession numbers of rDNA sequences are listed in Table 1. Some individuals of the species newly described were fixed in $70 \%$ ethanol under a cover-slip, stained with carmine, differentiated in acid-alcohol, dehydrated in serial concentrations of ethanol, cleared in xylene, and mounted in Canada balsam. The descriptive terminology and numbering of the haptoral parts follow Bu et al. (1999). Drawings were made from specimens originated from the same population used for molecular analyses. Measurements are presented in micrometres.

DNA extraction and PCR amplification. Prior to DNA extraction, individual parasites were removed from Bleasure's glue, placed in $0.5 \mathrm{ml}$ Eppendorf tubes and dipped in $500 \mu \mathrm{l}$ TE9 (500 mM Tris- $\mathrm{HCl}, 200 \mathrm{mM}$ EDTA, and $10 \mathrm{mM} \mathrm{NaCl}, \mathrm{pH}$ 9.0) for $2-3 \mathrm{~h}$. They were then placed in $0.5 \mathrm{ml}$ tubes containing $20 \mu 1$ lysis buffer $(0.45 \%$ NP-40, $0.45 \%$ Tween- $20,1 \mathrm{mM}$ EDTA, $10 \mathrm{mM}$ Tris- $\mathrm{HCl}$ and $20 \mu \mathrm{g} / \mathrm{ml}$ proteinase $\mathrm{K}$ ) and incubated at $65^{\circ} \mathrm{C}$ for $1 \mathrm{~h}$, followed by incubation at $95^{\circ} \mathrm{C}$ for 15 min to inactivate the proteinase $\mathrm{K}$.

A region comprising partial ssrDNA and the entire internal transcribed spacer 1 (ITS1) region was amplified using primers S1 (5'-ATTCCGATAACGAACGAGACT-3') and IR8 (5'-GCTAGCTGCGTTCTTCATCGA-3') as previously described (Šimková et al. 2003). Each amplification reaction was performed in a final volume of $50 \mu 1$ containing $9 \mu 1$ of lysate, $1.5 \mathrm{mM}$ of $\mathrm{MgCl}_{2}, 1 \times$ buffer (TakaRa), $200 \mu \mathrm{M}$ of each dNTP, $0.8 \mu \mathrm{M}$ of each PCR primer and $2.5 \mathrm{U}$ of Ex Taq polymerase (TakaRa) in a thermocycler (MJ Research) under the following conditions: $4 \mathrm{~min}$ at $95^{\circ} \mathrm{C}$ (initial denaturation), followed by 35 cycles of $1 \mathrm{~min}$ at $92^{\circ} \mathrm{C}$ (denaturation), $1 \mathrm{~min}$ at $53^{\circ} \mathrm{C}$ (annealing) and $1.5 \mathrm{~min}$ at $72^{\circ} \mathrm{C}$ (extension) and a final extension at $72^{\circ} \mathrm{C}$ for $10 \mathrm{~min}$.

The C1-D2 lsrDNA region was amplified using the universal primer $\mathrm{C} 1$ (5'-ACCCGCTGAATTTAAGCAT-3') and the reverse primer D2 (5'-TGGTCCGTGTTTCAAGAC-3'). Amplification was performed as described above, except that the lysate was $6 \mu 1$ in each reaction. The cycling conditions were as following: $5 \mathrm{~min}$ at $94^{\circ} \mathrm{C}$ (initial denaturation), followed by 30 cycles of $1 \mathrm{~min}$ at $94^{\circ} \mathrm{C}$ (denaturation), $1 \mathrm{~min}$ at $56^{\circ} \mathrm{C}$ (annealing) and $1 \mathrm{~min}$ at $72^{\circ} \mathrm{C}$ (extension) and a final extension at $72^{\circ} \mathrm{C}$ for $10 \mathrm{~min}$. Samples with host DNA or without genomic DNA were included in each amplification run as controls. PCR products were examined on $1 \%$ agarose gels, stained with ethidium bromide, and photographed upon transillumination.

DNA sequencing and phylogenetic analyses. Gel-purified PCR products were directly sequenced with the same primers as for PCR amplification using an ABI 377 automated DNA sequencer (BigDye Terminator Chemistry). The sequences were edited using the program Seqman ${ }^{\mathrm{TM}}$ (DNASTAR Inc.) and aligned using the program Clustal_X (Thompson et al. 1997), and the alignment was improved by eye. Analyses were carried out on all substitutions. Saturation level was assessed as in Desdevises (2001). The absence of saturation in the data was obvious, and allowed the use of the whole alignment for phylogenetic reconstruction. The phylogenetic trees were reconstructed using MEGA version 3.0 (Kumar S., Tamura K., Jakobsen I.B. and Nei M. 2004. MEGA: Molecular Evolutionary Genetics Analysis, Pennsylvania State University, University Park, and Arizona State University, Tempe). Phylogenetic analyses were performed based on neighbour-joining (NJ) and maximum-parsimony (MP) methods. In reconstructing the $\mathrm{NJ}$ tree, the Kimura-2-parameter model, correcting 
Table 1. List of parasite species used in this study with host species, locality, number of specimens measured/sequenced and GenBank ${ }^{\mathrm{TM}}$ accession numbers. Asterisks indicate species sequenced in this study.

\begin{tabular}{|c|c|c|c|c|}
\hline Parasite species & Host species & Locality & $\begin{array}{c}\text { No. of specimens } \\
\text { measured/sequenced }\end{array}$ & $\begin{array}{l}\text { GenBank No. } \\
\text { ssrDNA/lsrDNA }\end{array}$ \\
\hline *Pseudorhabdosynochus seabassi $\mathrm{sp} . \mathrm{n}$. & Lates calcarifer & Yangjiang, China & $50 / 4$ & $-/$ AY553620 \\
\hline *P. latesi (Tripathi, 1955) & Lates calcarifer & Yangjiang, China & $20 / 4$ & $-/$ AY553621 \\
\hline *P. lantauensis (Beverley-Burton et Suriano, 1981) & Epinephelus brunneus & Huidong, China & $20 / 4$ & AY553614/AY553624 \\
\hline *P. epinepheli (Yamaguti, 1938) & Epinephelus brunneus & Huidong, China & $10 / 4$ & AY553615/AY553622 \\
\hline${ }^{*}$ P. coioidesis $\mathrm{Bu}$, Leong, Wong, Woo et Foo, 1999 & Epinephelus coioides & Huiyang, China & $40 / 4$ & AY553616/AY553623 \\
\hline *Diplectanum sillagonum Tripathi, 1957 & Sillago sihama & Hainan, China & $10 / 4$ & AY553617/AY553626 \\
\hline${ }^{*} D$. grouperi $\mathrm{Bu}$, Leong, Wong, Woo et Foo, 1999 & Epinephelus coioides & Huidong, China & $40 / 4$ & AY553618/AY553628 \\
\hline${ }^{* D}$. blaiense Gupta et Khanna, 1974 & Sillago sihama & Hainan, China & $10 / 2$ & $-/ A Y 553627$ \\
\hline *D. veropolynemi Nagibina, 1976 & Polynemus sextarius & Huiyang, China & $10 / 2$ & $-/$ AY553625 \\
\hline D. aequans (Wagener, 1857) & Dicentrarchus labrax & Atlantic Ocean & - & AJ276439/- \\
\hline Lamellodiscus erythrini Euzet et Oliver, 1967 & Pagellus erythrinus & France & - & AJ276440/- \\
\hline L. ignoratus Palombi, 1943 & Diplodus annularis & France & - & AF294957/- \\
\hline L. verberis Euzet et Oliver, 1967 & Lithognathus mormyrus & France & - & AF294955/- \\
\hline *Dactylogyrus extensus Mueller et & Cyprinus carpio & Guangzhou, China & $40 / 7$ & AY553619/AY553629 \\
\hline
\end{tabular}

Table 2. Pairwise genetic distances (estimated using the Kimura-2-parameter model; in \% differences) for the C1-D2 lsrDNA sequences of the Pseudorhabdosynochus and Diplectanum species and Dactylogyrus extensus (outgroup).

\begin{tabular}{|r|l|c|c|c|c|c|c|c|c|c|c|}
\hline \multicolumn{2}{|c|}{ Species } & 1 & 2 & 3 & 4 & 5 & 6 & 7 & 8 & 9 & 10 \\
\hline 1 & P. coioidesis & 6.89 & & & & & & & & & \\
2 & P. lantauensis & 5.88 & 3.91 & & & & & & & \\
3 & P. epinepheli & 10.03 & 8.69 & 7.79 & & & & & & \\
4 & P. seabassi & 9.11 & 6.88 & 6.89 & 5.65 & & & & & \\
5 & P. latesi & 7.48 & 4.18 & 4.05 & 9.30 & 7.47 & & & & \\
6 & D. grouperi & 32.27 & 33.18 & 32.84 & 32.27 & 31.17 & 32.29 & & & \\
7 & D. blaiense & 30.83 & 30.90 & 31.22 & 32.62 & 29.80 & 29.81 & 8.46 & & \\
8 & D. sillagonum & 22.67 & 23.07 & 22.77 & 24.60 & 23.63 & 22.91 & 28.45 & 25.28 & \\
9 & D. veropolynemi & 45.53 & 46.86 & 45.66 & 49.60 & 50.02 & 46.95 & 53.30 & 51.72 & 47.38 & \\
10 & Dactylogyrus extensus & 45.62 & & & \\
\hline
\end{tabular}


for transition bias, was used to estimate the distances. To obtain the most-parsimonious tree, the Max-Mini Branch-and-bound search strategy was used in MP method. The robustness of the inferred phylogeny was assessed using a bootstrap procedure with 1,000 replications.

\section{RESULTS}

\section{Identification and description using morphology}

Pseudorhabdosynochus seabassi sp. n. Figs. 1-10

Description. Diplectanidae Bychowsky, 1957 (sensu Yamaguti, 1963); Pseudorhabdosynochus Yamaguti, 1958 (sensu Cycloplectanum as amended by Beverley-Burton and Suriano, 1981). Body slender; total length including haptor, 654 (582-727); width 233 (164-254) at level of ovary. Tegument armed with anteriorly-directed scales in the posterior half of the body. Head region with two pairs of dissimilar eye-spots. Mouth median, subterminal. Pharynx subspherical, 66 (51-73) long and 73 (45-103) wide. Oesophagus short, bifurcating posterior to pharynx; caeca running laterally to about three-quarter of body length, not joined at posterior end (Fig. 1).

Haptor 148 (140-192) long, with one ventral and one dorsal squamodisc, two pairs of hamuli, three bars, 14 marginal hooklets. Dorsal and ventral squamodiscs 111 (103-133) long and 140 (125-162) wide with 11-12 concentric rows of elements, none of which are completely fused (Fig. 9). Dorsal hamuli 41 (40-42) long (Fig. 5) and ventral hamuli 52 (45-56) long (Fig. 4). Two dorsal accessory bars 89 (86-94) long (Fig. 3); one ventral transverse bar 191 (180-197) long (Fig. 2), with transverse groove, gradually tapering into narrow tip; marginal hooklets 13 (12-15) long (Fig. 7).

Testis subspherical, posterior to ovary, intercaecal. Vas deferens originates from left side of testis, extending anteriorly before dilating to form seminal vesicle. Ejaculatory duct with spiral muscular bands opens into posterior region of MCO bulb with male accessory reservoir. MCO with bulbous base, slightly oval, 47 (37-56) long, with four concentric layers of apparent musculature. Distal part of MCO tubular, 85 (56-113) long (Fig. 6).

Ovary equatorial, intercaecal, pretesticular, distal region curved dorsoventrally around right intestinal caecum (Fig. 1). Vagina, 33 (28-38) in total length, is divided into two parts: partly sclerotized proximal part, lotus flower-shaped with slightly wavy rims, which may serve as seminal receptacle; and sclerotized distal part fibriform (Fig. 8). Eggs tetrahedral with rounded poles and long filament attached to one pole (Fig. 10).

T y p e host: Lates calcarifer Bloch (Centropomidae).

Site of infestation: Gill filaments.

$\mathrm{T}$ y $\mathrm{p}$ e 1 o c a $1 \mathrm{it}$ y: Yangjiang (in floating sea cages), Guangdong, China $\left(21^{\circ} 50^{\prime} \mathrm{N}, 111^{\circ} 58^{\prime} \mathrm{E}\right)$.
Add it i o n a 1 o c a lity: Hainan (in floating sea cages), China $\left(19^{\circ} 34^{\prime}-20^{\circ} 02^{\prime} \mathrm{N}, 109^{\circ} 30^{\prime}-53^{\prime} \mathrm{E}\right)$.

Deposition of type specimens: Holotype SYSZ0001374 and paratypes SYSZ0001375-84 in the Museum of Biology of Sun Yat-sen University, Guangdong Province, China; paratypes USNPC no. 95083 (four paratype slides) in the U.S. National Parasite Collection; 5 paratypes in the Institute of Parasitology, České Budějovice (coll. no. M-405). Other paratypes in the authors' collection.

No. of specimens studied:50.

E t y m o log $\mathrm{y}$ : The specific name refers to the common name of the fish host.

Remarks. A survey of the literature revealed that six species of Diplectanidae have been described from gills of Lates calcarifer, namely: Pseudorhabdosynochus latesi Tripathi, 1955, P. monosquamodiscusi Balasuriya et Leong, 1995, Diplectanum narimeen Unithan, 1964, D. setosus Nagibina, 1976, D. paralatesi Nagibina, 1976, and $D$. penangi Liang et Leong, 1991. The new species can be distinguished morphologically from the above six species based on the different shape of haptors and terminal genitalia. It is morphologically more similar to $P$. latesi and P. monosquamodiscusi than to any of the other species, based on the MCO structure (Fig. 13). But the new species can be readily distinguished from $P$. lates $i$ and $P$. monosquamodiscusi by the obviously different-shaped vagina, which is thistle-shaped in $P$. lates $i$ with wavy rims and a projection on the posterior end (Liang and Leong 1991), and is hourglass-shaped in $P$. monosquamodiscusi with wavy rims opening to left of median line (Balasuriya and Leong 1995). The new species also differs from $P$. monosquamodiscusi, as the dorsal squamodisc of the latter is absent.

\section{Molecular phylogenetic analyses}

When performing phylogenetic analyses, the partial ssrDNA sequence (the ITS1 sequence was not included for analysis because of high interspecific variability) of $437 \mathrm{bp}$ from $D$. grouperi was included in the alignment (the sequences from $P$. seabassi and $P$. latesi are not included because they could not be properly amplified), together with sequences of the same length from $P$. lantauensis, $P$. epinepheli, $P$. coioidesis, D. sillagonum, D. aequans, Lamellodiscus erythrini, L. ignoratus and $L$. verberis (see Table 1). This alignment resulted in 437 aligned positions, of which 77 are variable and 41 are parsimony-informative. When performing phylogenetic analyses using partial lsrDNA sequence data, the partial 1srDNA sequences of $881 \mathrm{bp}$ from $P$. seabassi and $P$. latesi were included, that of $D$. veropolynemi was added, that of $D$. aequans which was relatively scarce and hard to amplify, was replaced by D. blaiense. No lsrDNA sequences of Lamellodiscus spp. are in the database, nor were specimens representing Lamellodiscus spp. available in the present study. The analyses were based on 916 aligned positions, of which 470 are variable and 289 are informative for a phylogenetic analysis by parsimony. 
Wu et al.: Pseudorhabdosynochus seabassi sp. n.

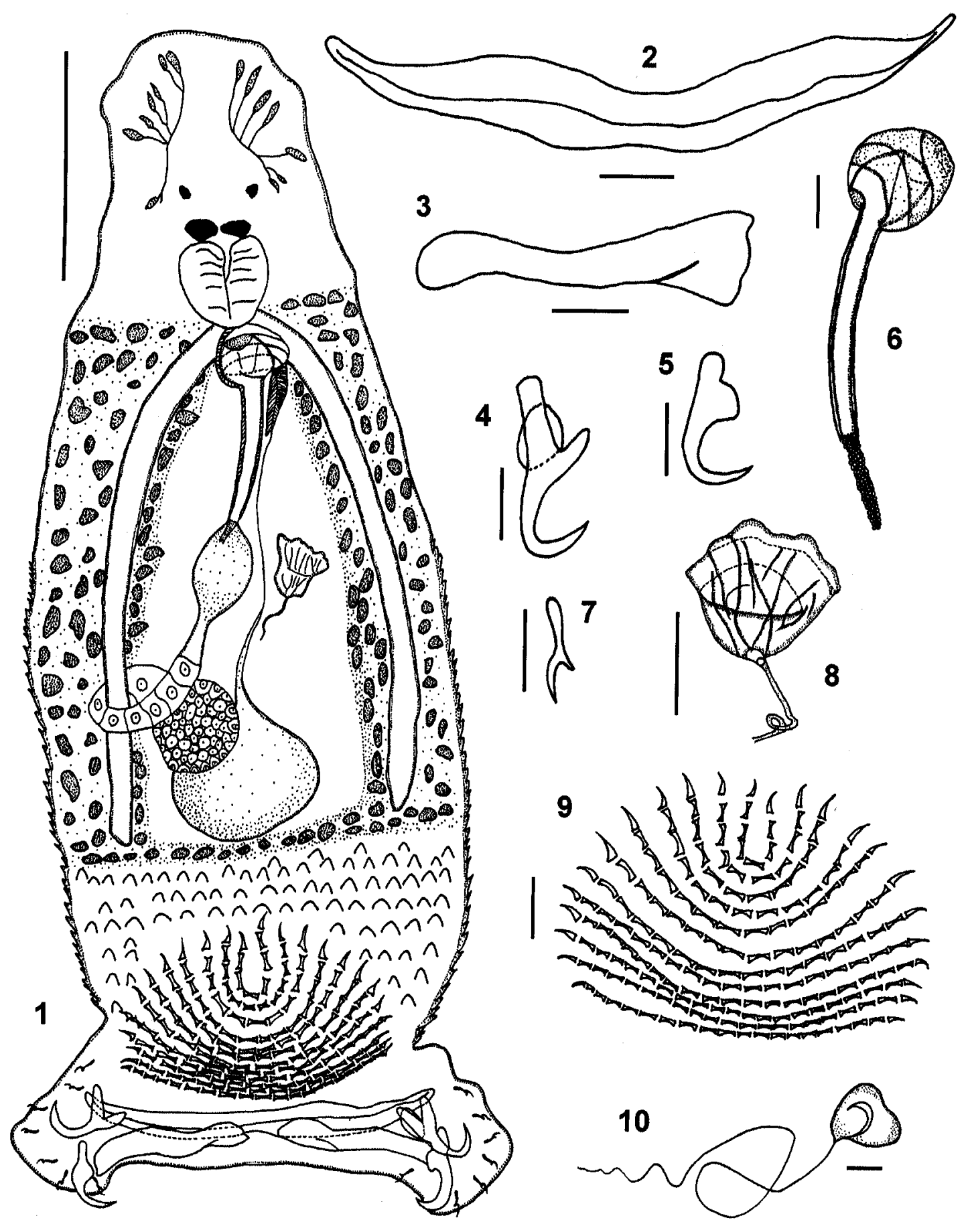

Figs. 1-10. Pseudorhabdosynochus seabassi sp. n. Fig. 1. Entire worm, ventral view. Fig. 2. Ventral bar. Fig. 3. Dorsal bar. Fig. 4. Ventral hamulus. Fig. 5. Dorsal hamulus. Fig. 6. Male copulatory organ. Fig. 7. Marginal hooklet. Fig. 8. Vagina. Fig. 9. Squamodisc. Fig. 10. Egg with long filament. Scale bars: Fig. $1=100 \mu \mathrm{m} ;$ Figs. $2-6,8-10=20 \mu \mathrm{m} ;$ Fig. $7=10 \mu \mathrm{m}$.

The validity and phylogenetic position of the new species described here is confirmed by measuring the genetic distances (estimated using the Kimura-2-parameter model) using partial lsrDNA data. No intraspecific variation in $P$. seabassi and differences ranging from
3.91 to $10.03 \%$ between Pseudorhabdosynochus species and 8.46 to $28.45 \%$ between Diplectanum species (D. grouperi not included) were observed in the present study (Table 2). 

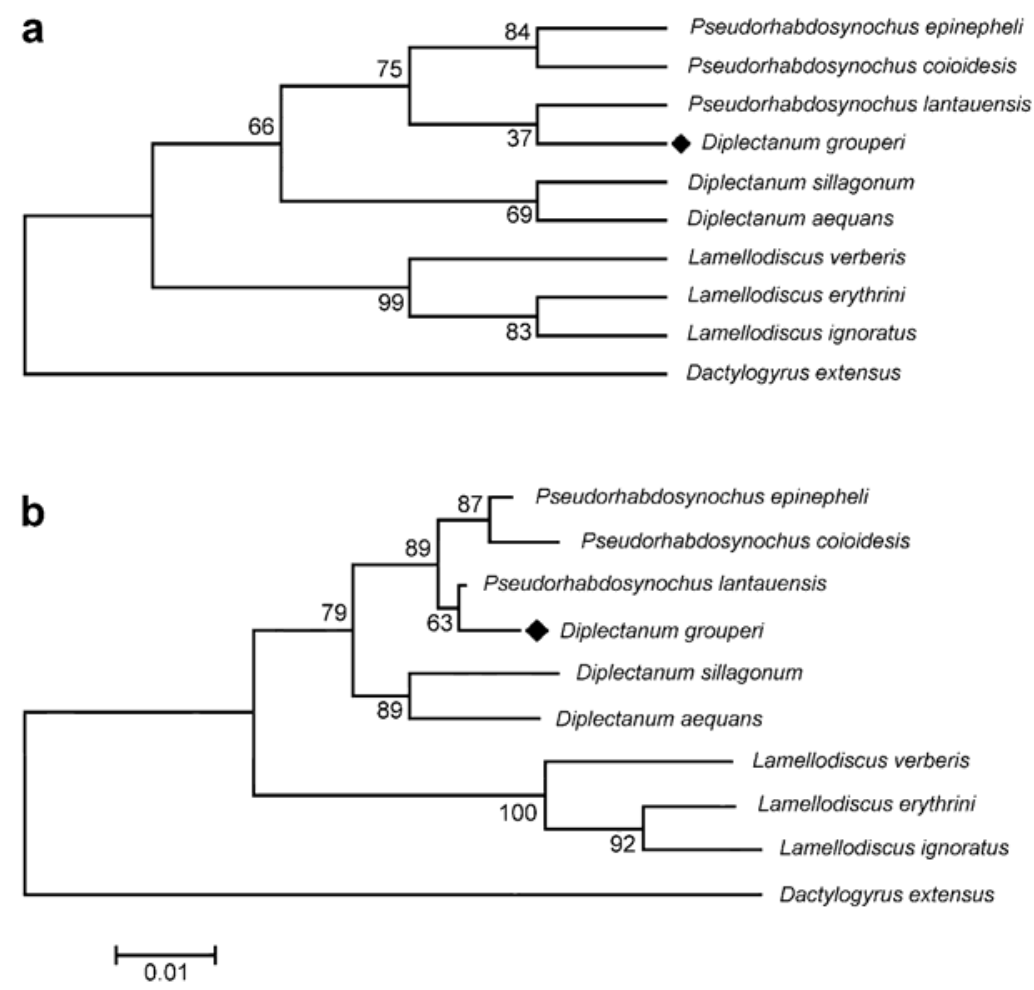

Fig. 11. Most-parsimonious (MP) tree (a) and neighbour-joining (NJ) tree (b) obtained using partial ssrDNA sequences from nine diplectanid species by Max-Mini Branch-and-bound searching strategy using Dactylogyrus extensus as the outgroup. Bootstrap values are indicated on the branches. For NJ tree, values for Kimura-2-parameter corrected models are shown.
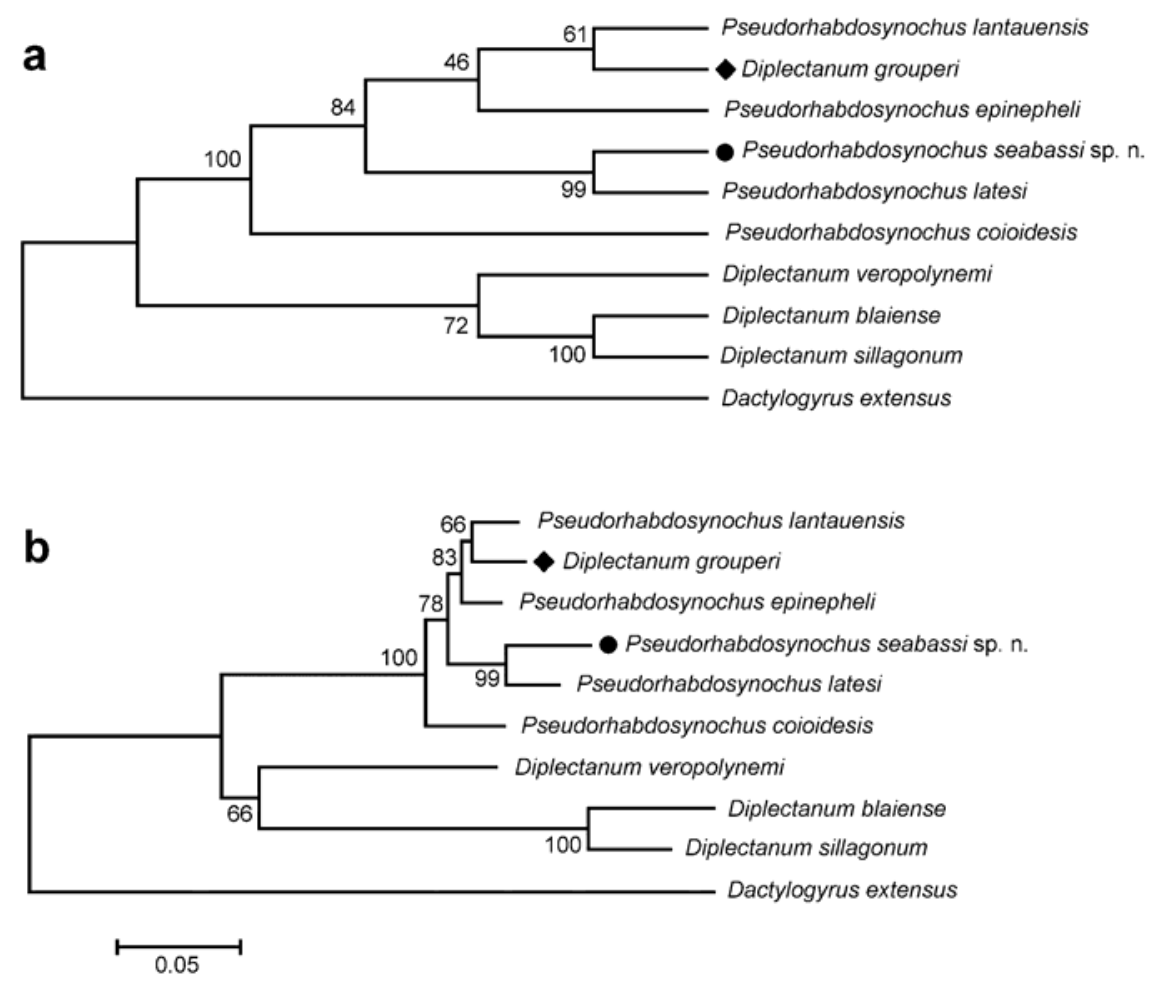

Fig. 12. Most-parsimonious (MP) tree (a) and neighbour-joining (NJ) tree (b) obtained using partial lsrDNA sequences from nine diplectanid species by Max-Mini Branch-and-bound searching strategy using Dactylogyrus extensus as the outgroup. Bootstrap values are indicated on the branches. For NJ tree, values for Kimura-2-parameter corrected models are shown. 
Both maximum-parsimony (MP) and the neighbourjoining (NJ) distance methods of phylogenetic reconstruction unequivocally place $D$. grouperi amongst Pseudorhabdosynochus using either ssrDNA or lsrDNA sequence data (Figs. 11 and 12, respectively). While there are different tree topologies when using ssrDNA and lsrDNA data sets, each data set yielded trees with identical topologies using both the MP and NJ methods of phylogenetic reconstruction.

When the partial ssrDNA sequence data set was used, MP analysis yielded a single most-parsimonious tree (length $=116 ; \mathrm{CI}=0.828 ; \mathrm{RI}=0.744$ ) with Max-Mini Branch-and-bound search strategy and equally-weight transitions and transversions, using Dactylogyrus extensus as the outgroup (Fig. 11a). Phylogenetic analyses using both MP and NJ methods revealed that the group consisting of $D$. grouperi and $P$. lantauensis was the sister group to the one comprising $P$. epinepheli and $P$. coioidesis. These two groups clustered together and were the sister group to that comprising $D$. sillagonum and $D$. aequans. A clear distinction was shown between the group consisting of three Lamellodiscus species and the group consisting of species in Pseudorhabdosynochus and Diplectanum (Fig. 11).

The same phylogenetic relationship between Pseudorhabdosynochus and Diplectanum as presented above was also indicated using partial lsrDNA sequence data when three species of Lamellodiscus were not included. The MP tree (length $=835 ; \mathrm{CI}=0.782 ; \mathrm{RI}=0.647$ ) and the same topological NJ tree supported by high bootstrap value are shown in Fig. 12. Pseudorhabdosynochus seabassi (marked with a solid circle) is phylogenetically more similar to $P$. latesi, which is in accordance with morphological analysis. Diplectanum grouperi grouped with $P$. lantauensis. These species and $P$. epinepheli clustered together as the sister group to the species from seabass. In the two phylograms derived from 1srDNA data, however, $P$. epinepheli and $P$. coioidesis were not presented as sister species, different from that when partial ssrDNA sequence data were used. The high bootstrap value, however, suggests that $P$. coioidesis is the sister group to the other four Pseudorhabdosynochus species and D. grouperi. The Diplectanum species (with the exception of D. grouperi) clearly group together (Fig. $12 b)$.

\section{DISCUSSION}

The accurate identification of diplectanids to species level is central to infection diagnosis and has important implications for studying their epidemiology and controlling the diseases they cause. A total of 24 species of Pseudorhabdosynochus have been reported, mostly from Epinephelus spp. (Balasuriya and Leong 1995, Santos et al. 2000), prior to the present study, namely, P. americanus (Price, 1937), P. amplidiscatus (Bravo-Hollis, 1954), P. beverleyburtonae (Oliver, 1984), P. bocquetae (Oliver et Paperna, 1984), P. caballeroi (Oliver, 1984), $P$. capurroi Vidal-Martinez et Mendoza-Franco, 1998, $P$. coioidesis Bu, Leong, Wong, Woo et Foo, 1999, P. cupatus (Young, 1969), P. epinepheli (Yamaguti, 1938), $P$. hargisi (Oliver et Paperna, 1984), P. kritskyi Dyer, Williams et Bunkley-Willams, 1995, P. lantauensis (Beverley-Burton et Suriano, 1981), P. latesi (Tripathi, 1955), P. magnisquamodiscum (Aljoshkina, 1984), P. melanesiensis (Laird, 1958), P. monaensis Dyer, Williams et Bunkley-Willams, 1994, P. monosquamodiscusi Balasuriya et Leong, 1995, P. querni (Yamaguti, 1968), P. riouxi (Oliver, 1986), P. serrani (Yamaguti, 1953), $P$. sulamericanus Santos, Buchmann et Gibson, 2000, $P$. summanae (Young, 1969), P. vagampullum (Young, 1969), and P. yucatanensis Vidal-Martinez, AguirreMacedo et Mendoza-Franco, 1997.

Since Cycloplectanum Oliver, 1968 was considered a junior synonym of Pseudorhabdosynochus Yamaguti, 1958, variations in haptor morphology have not been used as the main characters to distinguish genera (Beverley-Burton and Suriano 1981, Kritsky and Beverley-Burton 1986). Consequently, the structure of the terminal genitalia, especially the $\mathrm{MCO}$, has been considered important in the identification and classification of diplectanid species and genera (Kritsky and Beverley-Burton 1986, Balasuriya and Leong 1995, Santos et al. 2000). Some diplectanid species from $L$. calcarifer were placed in Pseudorhabdosynochus by Kritsky and Beverley-Burton (1986). However, there have been some controversies as to the validity of the classification of these species (Balasuriya and Leong 1995, Zhang J.-Y., Guangzhou, China; pers. comm.), as their MCOs are markedly different from those of the other species of Pseudorhabdosynochus (Fig. 13). The typical proximal part of the MCO in species of Pseudorhabdosynochus is reniform, heavily sclerotized, and divided into four chambers (Fig. $13 \mathrm{a}-\mathrm{c}$ ), whereas diplectanids from $L$. calcarifer have a bulbous proximal region with four concentric layers of apparent muscular origin instead of the reniform structure has four compartments (Fig. 13 $\mathrm{d}-\mathrm{f}$ ). In this study, partial lsrDNA sequence data were used to reconstruct the phylogenetic relationship of these two groups which have distinct difference in $\mathrm{MCO}$ morphology. The result has revealed that these two groups could cluster together well (Fig. 12). Therefore, the distinctness of the MCO structure between species of Pseudorhabdosynochus could be considered as an intrageneric difference.

Diplectanum species are considered to be uncommon parasites of Epinephelus spp. (Bu et al. 1999), and so far only D. echinophallus Euzet et Oliver, 1965 from $E$. gigas and D. grouperi from E. coioides have been described. In this study, however, phylogenetic analyses with both MP and NJ methods using both partial ssrDNA and lsrDNA data sets grouped D. grouperi with Pseudorhabdosynochus spp. and suggested that D. grouperi is the sister species of $P$. lantauensis (Figs. 11, 12). This result is inconsistent with that of morphological observations, as the $\mathrm{MCO}$ of $D$. grouperi is 

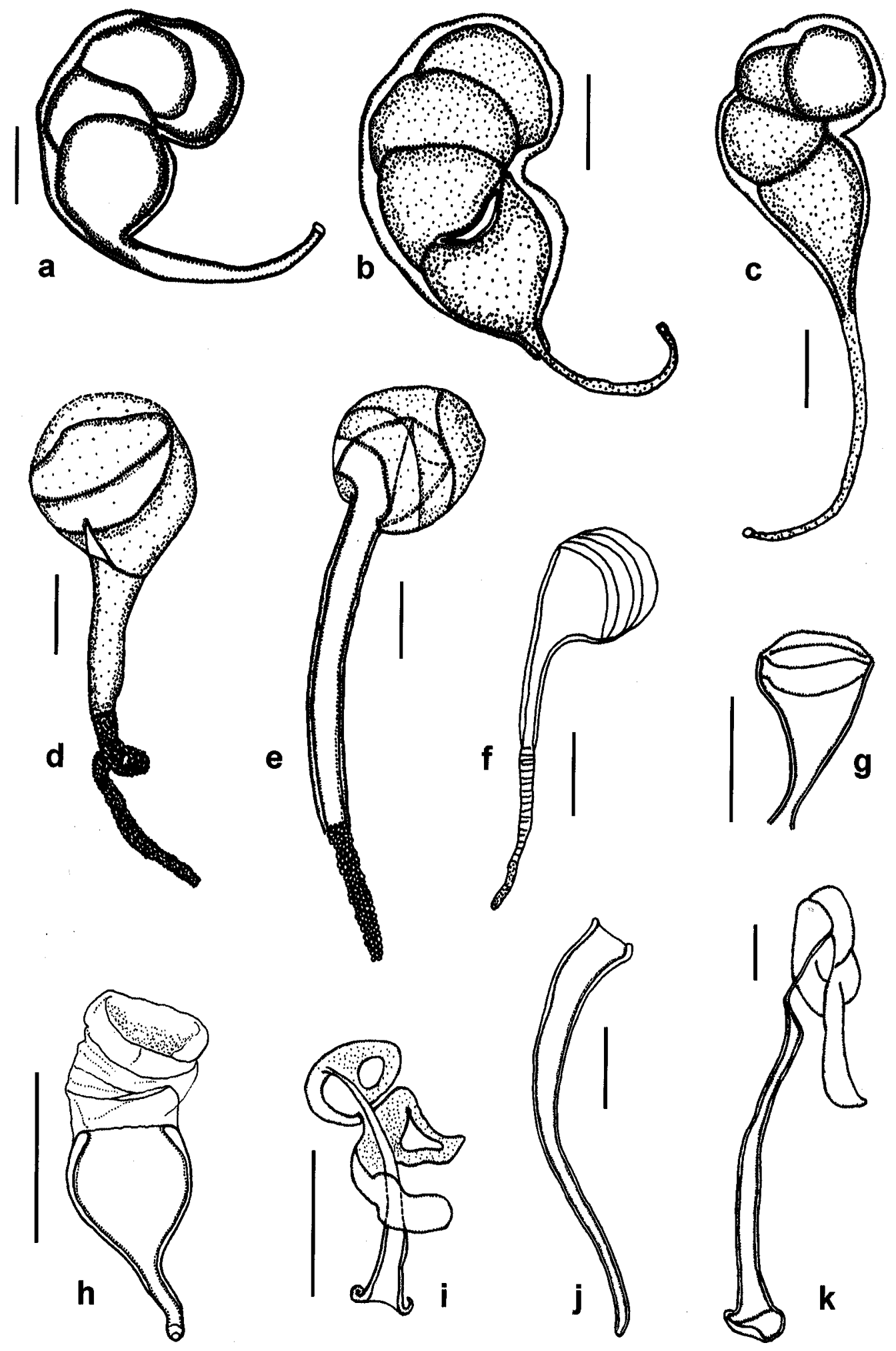

Fig. 13. Male copulatory organs of different Pseudorhabdosynochus and Diplectanum species. a - P. lantauensis; b - P. epinepheli; $\mathbf{c}-P$. coioidesis; $\mathbf{d}-P$. latesi $; \mathbf{e}-P$. seabassi $; \mathbf{f}-P$. monosquamodiscusi $; \mathbf{g}-D$. grouperi $; \mathbf{h}-D$. monticellii (from Domingues and Boeger 2003); $\mathbf{i}-D$. sillagonum; $\mathbf{j}-D$. veropolynemi; $\mathbf{k}-D$. blaiense. Scale bars: $20 \mu \mathrm{m}$. 
sclerotized, cup-shaped, the wide proximal part has four concentric muscular layers and the distal part is tubular (Fig. 13 g), whereas in Pseudorhabdosynochus spp., this organ is clearly different (Fig. 13 a-f). Similar structures of MCO are also found in D. echinophallus and $D$. monticellii Domingues et Boeger, 2003 from Cynoscion spp. (Sciaenidae) (Fig. 13 h). However, three other species of Diplectanum used in the present study have typically tubular-shaped MCOs with or without a proximal part (Fig. $13 \mathrm{i}-\mathrm{k}$ ). Though the function of the four concentric muscular layers in the proximal part of the MCO is unknown (Balasuriya 1994), we believe that this structure is important for understanding the evolution of these parasites.

The 3' terminal portion of the ssrDNA and 5' terminal portion of the lsrDNA have been widely used to estimate phylogenetic relationships among monogeneans (e.g., Cunningham et al. 1995, Mollaret et al. 1997, 2000, Littlewood et al. 1998, Desdevises et al. 2000, Chisholm et al. 2001, Jovelin and Justine 2001, Olson and Littlewood 2002). Desdevises (2001) studied the phylogenetic position of Furnestinia echeneis (Diplectanidae), which was moved to Lamellodiscus based on the V4 region of ssrDNA sequence, and concluded that Furnestinia and Lamellodiscus should be synonymized. As proposed by Desdevises (2001), F. echeneis is a Lamellodiscus with only one lamellodisc, which indicates that the taxonomy of the Diplectanidae mainly based on the haptoral adhesive organ structure may not be appropriate. In the present study, the phylogenetic position of D. grouperi was examined using two different DNA regions and the same results were obtained (Figs. 11, 12). We propose that $D$. grouperi from E. coioides should be included in Pseudorhabdosynochus as $P$. grouperi comb. n. based on robust molecular phylogenetic evidence. It appears from these observations that we should consider many mor- phological characters rather than only one or few when addressing a taxonomic problem. Moreover, it has been argued (e.g., Nadler et al. 2000) that the phylogenetic species concept should be used for species delineation rather than a comparative (i.e. yardstick) approach.

In this study, the phylogenetic positions of $P$. seabassi and $P$. latesi were investigated using molecular data sets for the first time. However, there was discordance regarding the relationship between $P$. epinepheli and $P$. coioidesis when different fragments were used, though there was consistency in showing the respective monophyly of Diplectanum (excluding D. grouperi) and Pseudorhabdosynochus (including D. grouperi). This is not surprising because some previous studies have reported similar discordance when different data sets were used for analysis (e.g., Cunningham et al. 1995, Littlewood et al. 1998, 1999, Litvaitis and Rohde 1999, Mollaret et al. 2000, Olson and Littlewood 2002). If we want to better understand such discordance, more species should be used in estimating phylogenetic relationships among species and more DNA markers displaying various evolutionary rates should be utilized. Overall, given that the present study has demonstrated variation in the morphology of the MCO in Pseudorhabdosynochus, more DNA data sets should be used to study the molecular phylogeny and systematics of diplectanids, in particular Diplectanum species whose MCOs have an open cup-like proximal part and narrow tubular distal part, such as D. echinophallus and D. monticellii.

Acknowledgements. Project support was provided by the National Natural Science Foundation of China (grant no. 30170124) to AXL, and the China National Funds for Distinguished Young Scientists (no. 30225033) to XQZ. The authors are grateful to Prof. Zhang Jian-Ying for his assistance in the identification of specimens.

\section{REFERENCES}

BALASURIYA L.K.S.W. 1994: Some ecological and pathological studies of gill monogeneans in floating cage cultured seabass Lates calcarifer (Bloch). PhD thesis. University Sains Malaysia, Penang, 169 pp.

BALASURIYA L.K.S.W., LEONG T.S. 1995: Pseudorhabdosynochus monosquamodiscusi $\mathrm{n}$. sp. (Monogenea: Diplectanidae) from Lates calcarifer cultured in floating cages in Malaysia. J. BioSci. 6: 30-34.

BEVERLEY-BURTON M., SURIANO D.M. 1981: A revision of Cycloplectanum Oliver, 1968 (Monogenea: Diplectanidae) and description of $C$. hongkongensis n. sp. and $C$. lantauensis n. sp. from Epinephelus spp. (Serranidae) in the South China Sea. Can. J. Zool. 59: 1276-1285.

BU S.S.H., LEONG T.S., WONG S.Y., WOO Y.S.N., FOO R.W.T. 1999: Three diplectanid monogeneans from marine finfish (Epinephelus spp.) in the Far East. J. Helminthol. 73: 301-312.
CHENG Q.-T., ZHEN B.-S. 1987: Systematic Synopsis of Chinese Fishes. Science Press, Beijing, 1458 pp. (In Chinese.)

CHISHOLM L.A., MORGAN J.A.T., ADLARD R.D., WHITTINGTON I.D. 2001: Phylogenetic analysis of the Monocotylidae (Monogenea) inferred from 28S rDNA sequences. Int. J. Parasitol. 31: 1253-1263.

CUNNINGHAM C.O., McGILLIVRAY D., MacKENZIE K. 1995: Phylogenetic analysis of Gyrodactylus salaris based on the small subunit (18S) ribosomal RNA gene. Mol. Biochem. Parasitol. 71: 139-142.

DESDEVISES Y. 2001: The phylogenetic position of Furnestinia echeneis (Monogenea, Diplectanidae) based on molecular data: a case of morphological adaptation? Int. J. Parasitol. 31: 205-208.

DESDEVISES Y., JOVELIN R., JOUSSON O., MORAND S. 2000: Comparison of ribosomal DNA sequences of $L a$ - 
mellodiscus spp. (Monogenea, Diplectanidae) parasitising Pagellus (Sparidae, Teleostei) in the North Mediterranean Sea: species divergence and coevolutionary interactions. Int. J. Parasitol. 30: 741-746.

DESDEVISES Y., MORAND S., JOUSSON O., LEGENDRE P. 2002: Coevolution between Lamellodiscus (Monogenea: Diplectanidae) and Sparidae (Teleostei): the study of a complex host-parasite system. Evolution 56: 2459-2471.

DOMINGUES M.V., BOEGER W.A. 2003: Neotropical Monogenoidea. 43. Diplectanum monticellii n. sp. (Diplectanidae) from the gills of Cynoscion leiarchus (Perciformes: Sciaenidae) in Brazil. J. Parasitol. 89: 698-700.

HUYSE T., AUDENAERT V., VOLCKAERT F.A.M. 2003: Speciation and host-parasite relationships in the parasite genus Gyrodactylus (Monogenea, Platyhelminthes) infecting gobies of the genus Pomatoschistus (Gobiidae, Teleostei). Int. J. Parasitol. 33: 1679-1689.

JOVELIN R., JUSTINE J.-L. 2001: Phylogenetic relationships within the polyopisthocotylean monogeneans (Platyhelminthes) inferred from partial 28S rDNA sequences. Int. J. Parasitol. 31: 393-401.

KRITSKY D.C., BEVERLEY-BURTON M. 1986: The status of Pseudorhabdosynochus Yamaguti, 1958 and Cycloplectanum Oliver, 1968 (Monogenea: Diplectanidae). Proc. Biol. Soc. Wash. 99: 17-20.

LEONG T.S. 1994: Parasites and diseases of cultured marine fin fishes in South East Asia. University Sains Malaysia, Penang, $25 \mathrm{pp}$.

LEONG T.S., WONG S.Y. 1990: Parasites of healthy and diseased juvenile grouper (Epinephelus malabaricus Bloch $\&$ Schneider) and seabass (Lates calcarifer Bloch) in floating cages in Penang, Malaysia. Asian Fish. Sci. 3: 319-327.

LIANG K.S., LEONG T.S. 1991: A redescription of Pseudorhabdosynochus latesi (Tripathi 1955) and description of Diplectanum penangi $\mathrm{n}$. sp. from Lates calcarifer cultured in floating cages in Malaysia and Thailand. J. BioSci. 2: $77-84$.

LITTLEWOOD D.T.J., ROHDE K., BRAY R.A. 1999: Phylogeny of the Platyhelminthes and the evolution of parasitism. Biol. J. Linn. Soc. 68: 257-287.

LITTLEWOOD D.T.J., ROHDE K., CLOUGH K.A. 1998: The phylogenetic position of Udonella (Platyhelminthes). Int. J. Parasitol. 28: 1241-1250.

LITVAITIS M.K., ROHDE K., 1999: A molecular test of platyhelminth phylogeny: inferences from partial $28 \mathrm{~S}$ rDNA sequences. Invertebr. Biol. 118: 42-45.

MO T.A. 1991: Variations of opisthaptoral hard parts of $G y$ rodactylus salaris Malmberg, 1957 (Monogenea, Gyrodactylidae) on parr of Atlantic salmon (Salmo salar L.) in laboratory experiments. Syst. Parasitol. 20: 11-19.

MOLLARET I., JAMIESON B.G.M., ADLARD R.D., HUGALL A., LECOINTRE G., CHOMBARD C., JUSTINE J.-L. 1997: Phylogenetic analysis of the Monogenea and their relationships with Digenea and Eucestoda inferred from 28S rDNA sequences. Mol. Biochem. Parasitol. 90: 433-438.
MOLLARET I., JAMIESON B.G.M., JUSTINE J.-L. 2000: Phylogeny of the Monopisthocotylea and Polyopisthocotylea (Platyhelminthes) inferred from 28S rDNA sequences. Int. J. Parasitol. 30: 171-185.

NADLER S.A., ADAMS B.J., LYONS E.T., DELONG R.L., MELIN S.R. 2000: Molecular and morphometric evidence for separate species of Uncinaria (Nematoda: Ancylostomatidae) in California sea lions and northern fur seals: hypothesis testing supplant verification. J. Parasitol. 86: 1099-1106.

NASH G., ANDERSON I.G., SHARIFF M., SHAMSUDIN M.N. 1987: Bacteriosis associated with epizootic in giant sea perch, Lates calcarifer, and the estuarine grouper, Epinephelus tauvina, cage cultured in Malaysia. Aquaculture 67: 105-111.

OLIVER G. 1968: Recherches sur les Diplectanidae (Monogenea) parasites de Téléostéens du golfe du Lion. I. Diplectaninae Monticelli, 1903. Vie Milieu, sér. A, Biol. Mar., 19: 95-138.

OLIVER G. 1987: Les Diplectanidae Bychowsky, 1957 (Monogenea, Monopisthocotylea, Dactylogyridea). Systématique. Biologie. Ontogénie. Ecologie. Essai de phylogenèse. Université des Sciences et Techniques du Languedoc, Montpellier, Thèse de Doctorat d'Etat, mention Sciences, $443 \mathrm{pp}$.

OLIVER G. 1993: Les Diplectanidae Bychowsky, 1957 (Monogenea, Monopisthocotylea, Dactylogyridea) marqueurs biologiques, temoins de la biogéographie et de l'évolution de leurs hôtes. Bull. Soc. Zool. Fr. 118: 25-36.

OLSON P.D., LITTLEWOOD D.T.J. 2002: Phylogenetics of the Monogenea - evidence from a medley of molecules. Int. J. Parasitol. 32: 233-244.

SANTOS C.P., BUCHMANN K., GIBSON D.I. 2000: Pseudorhabdosynochus spp. (Monogenea: Diplectanidae) from the gills of Epinephelus spp. in Brazilian waters. Syst. Parasitol. 45: 145-153.

ŠIMKOVÁ A., PLAISANCE L., MATĚJUSOVÁ I., MORAND S., VERNEAU O. 2003: Phylogenetic relationships of the Dactylogyridae Bychowsky, 1933 (Monogenea: Dactylogyridea): the need for the systematic revision of the Ancyrocephalinae Bychowsky, 1937. Syst. Parasitol. 54: 1-13.

THOMPSON J.D., GIBSON T.J., PLEWNIAK F., JEANMOUGIN F., HIGGINS D.G. 1997: The Clustal_X windows interface: flexible strategies for multiple sequence alignment aided by quality analysis tools. Nucl. Acids Res. 24: 4876-4882.

WU B.-H., LONG S., WANG W.-J. 2000: Fauna Sinica: Platyhelminthes Monogenea. Science Press, Beijing, China, 756 pp. (In Chinese.)

YAMAGUTI S. 1963: Systema Helminthum. Vol. 4. Monogenea and Aspidocotylea. Interscience Publishers, New York, London, 699 pp.

ZHANG J.-Y., YANG T.-B., LIU L. 2001: [Monogeneans of Chinese Marine Fishes.] Agriculture Press, Beijing, China, 400 pp. (In Chinese.) 